\title{
A STUDY BASED ON THE EFFECT OF STRATEGIC ORIENTATION ON MANAGEMENT INNOVATION AND HUMAN RESOURCE MANAGEMENT OF A BUSINESS
}

\author{
Ruan $\mathrm{LEI}^{1}-$ Zhang $\mathrm{YAN}^{2}-$ Peng $\mathrm{LEI}^{3}$ \\ ${ }^{1}$ Scool of Management, Jilin University, Changchun Jilin China, 130022, No. 5988, \\ Renmin Street, Nanguan District, Changchun, Jilin Province, China. \\ E-mail: ruanlei13@mails.jlu.edu.cn \\ ${ }^{2}$ Scool of Management, Jilin University, Changchun Jilin China, 130022, No. 5988, \\ Renmin Street, Nanguan District, Changchun, Jilin Province, China. \\ E-mail: zhangyanjd@126.com (corresponding author) \\ ${ }^{3}$ College of Foreign Languages, Jilin University, Changchun Jilin China, 130012, No. 2699, \\ Qianjin Street, Chaoyang District, Changchun, Jilin Province, China. \\ E-mail:penglei14@mails.jlu.edu.cn
}

Investigation on human resource role is progressing, and the influence of fits between human resources and business strategies have been confirmed in various studies. Such influence has also been proven as a good way to acquire organizational competitive advantages and achieve the optimal operating performance. Under such a context, a new variable, Management Innovation, is included in this study to observe the effects of such a practical and changeable variable on strategic orientation and human resource management role.

Top ten businesses in Fujian Province are selected for the questionnaire survey. Total 500 copies of questionnaire are distributed and 376 valid copies are retrieved, with the retrieval rate $75 \%$. The research results show the positive effects of 1 . strategic orientation on management innovation, 2. strategic orientation on human resource management role, and 3. management innovation on human resource management role. It expects to verify richer and multiple effects in this study for the reference of successive research and the practice.

Keywords: strategic orientation, management innovation, human resource management role 


\section{INTRODUCTION}

In such a knowledge economic era, human resources are one of the major competitive advantages of a business. Moreover, the explosive growth of the ten-time era has resulted in innovative products and markets that the industrial environmental changes have become violent. Working out management measures of fits to cope with organizational development is an attractive issue; human resources are no exception. The viewpoint of strategic human resource management has been proposed; organizational strategies have to fit for human resource management practice in order to acquire organizational competitive advantages and achieve the optimal operating performance.

Human resource roles have been constantly discussed in the academic circle, and it is indicated that human resource roles are largely different from those in the past as the change of human resource roles would become a trend. Past human resource roles were traditional roles engaging in administrative support; future human resource departments should play the role of strategic partners of a business, participating in business strategic planning, understanding future development and human resource demands, establishing human capitals with competitive advantages, or expanding the power and capabilities, and developing more innovative and prospective also presented the consistent opinion about the increasing weight of human resource roles in business strategies.

Human resource roles are constantly changing. According to the fiercely environmental changes in industries, human resource roles would appear new development, which is worth further investigation. However, what will be the development? It requires continuous exploration of the role of how human resources contribute to business competitive advantages. Besides, the consistent integration of management systems and organizational strategies would result in better performance; therefore, human resource roles should be transformed when an organization applies distinct strategic orientation. Such a point of view is the research motivation in this study.

\section{LITERATURE REVIEW}

\subsection{Strategic orientation}

Chen et al. (2013) regarded strategies as the decision of a business's long-term objectives as well as the movement and resource allocation to achieve such objectives. The strategic orientation reflects the appropriate practice of a business 
pursuing permanent performance (Deshpande et al. 2013). Strategic orientation is a specific route with which an organization tends to continuously acquire dominant performance (Hwang and Tsai 2011). A strategic route to provide a series of policies and instructions and assist an organization in continuous promotion could enhance the competitive potential and contribute to the performance development (Komninos et al. 2011). Sheng et al. (2011) also regarded strategic orientation of an organization as a factor in the sustainable competitiveness. Weske (2012) indicated that the definitions of strategic orientation, strategic styles, and strategic types in past research on strategies presented high repetition, but the idea of strategic orientation could more accurately present the process of a business effectively applying the resources and selecting the best competitive strategies to compete with other businesses in the same industry. Strategic orientation could better reflect the actual tendency and degree of decision-making in a business, rather than simple classification, that it was more suitable for empirical research. Williamson et al. (2013) argued that strategic orientation was the determinant for the sustainable competitiveness of a business. For this reason, a business should have its own strategic orientation for the competitive advantages. The strategies discussed in this study indeed are the high-level decisionmaking in an organization, determining the direction and operation points of a company. A strategy is like a key in the organizational survival; an organization could open new opportunities with a right key; otherwise, the negative effects on the organization could result in decline.

In Tallon and Pinsonneault's (2011) study on strategic orientation and human resource practice, organizational strategic orientation was classified into three categories. 1. Cost orientation: An organization needed the capabilities to reduce all investment costs; the expenses from manufacturing to operation had to be lowered. An organization therefore could increase the monitoring and control system and reduce the investment in the development of the organization and the employees. 2. Quality orientation: An organization focused on the transformation of investment to output and expected to increase the reliability of all products and satisfy customers. An organization could focus on the quality-oriented strategy through quality improvement or investment in professional training and performance management. 3. Innovation orientation: Similar to the prospectors in the strategic matrix proposed by Sheng et al. (2011), a company would invest in new product and new market development, stress on personnel education and human resource development to enhance the quality of humanism, or create innovative atmosphere in the organization to concentrate on the innovative strategic orientation. The above categories are applied to this study. 


\subsection{Management innovation}

Avci et al. (2011) mentioned that Management Innovation was first proposed by Evan and Black, who pointed out Management Innovation as the innovation of organizational structure and management process, including organization and personnel innovation, and correlated to the basic operation and business management of the organization (Chung 2011). In the research on the correlation between organizational innovation and performance, Engeström and Glăveanu (2012) considered that Management Innovation of an organization existed in the "social system", which referred to an organization completing a unique objective and task through the interaction among members and containing organizational norms, responsibility of role, and program and organizational structure related to the organizational members. Management Innovation therefore was defined as an organization being able to practice a new approach to broadly apply to the organizational process and structure, such as recruiting staff, resource allocation, and constructing work responsibilities, power, and reward systems. Ismail et al. (2013) proposed to interpret Management Innovation with six functions of an organization, naming planning, organization, employment, leadership, control, and service. Management Innovation was further divided into "employment and leadership innovation" and "organization and planning innovation" with Exploratory Factor Analysis (EFA). Luftman and Derksen (2012) regarded Management Innovation in service industry as an organization applying new approaches to service planning \& budgeting and improvement \& management processes. Tallon and Pinsonneault (2011) pointed out Management Innovation as new measures for the internal management of an organization to enhance the business performance.

Williamson et al. (2013) defined Management Innovation as the innovation of organizational structure and process in a business and indicated that Management Innovation reflected the rapid changes in current environments with which a business could make proper changes to cope and further present innovation on the organizational structure and process. The definition is applied to this study, where Management Innovation is divided into two dimensions. 1. Structural innovation: A business broadly applies a new approach or system to the organizational structure of a business in order to cope with the environment. 2. Process innovation: A business could efficiently practice the basic operation and achieve customer satisfaction to reduce the costs; as a result, the business could continuously grow and avoid being eliminated by external environments. 


\subsection{Human resource management role}

Black (2011) indicated that the most competitive US businesses in 1988-1991 focused the human resource operation on the transition from operational to completely strategic status. Such a statement was proven in a lot of successive research (Chung 2012). Human resources could add value to a business by being the partner of the line manager. When the internal management of an organization is linked with the external demands of a business with human resources, human resource profession becomes the value added process for the organization (Fenton and Langley 2011). When stating human resource roles as the process of a business adding value, Kane and Borgatti (2011) did not focus on human resource roles transiting from operational to strategic role, but pointed out the complicated or sometimes paradoxical role (Marti et al. 2013). Four routes for human resource possibly adding value to a business were proposed, including executing strategy, building infrastructure, ensuring employee contribution, and management transformation and change. Wang and Cheng (2012) pointed out the same point of view and argued that a business could acquire competitive advantages when the human resource manager and the line manager could collaborate to integrate human resources for the organizational demands. Kane and Borgatti (2011) also mentioned that an ideal organization would have the human resource manager and the line manager collaborate to solve personnel problems.

Kane and Borgatti (2011) considered that human resource role should change with the operational strategy of an organization and divided it into four roles, which are applied to this study.

1. Transaction, the intermediate role between employers and employees, including the basic administrative functions of signing and termination of employment contracts, salary and welfare operation, employees' attendance and promotion records, and other personnel administrative operation.

2. Translation referred to listening and responding to the issues which the employees concerned, interpreting policies, and revising regulations. It played the role of a bridge for communication and information delivery between employees and managers, and even between employees and external customers.

3. Transition, on one hand, could implement human resource management activities and strategies and, on the other hand, could improve the operational strategic objectives and provide the organization with motivation to change, such as assisting in proceeding major policies and integrating human resources in mergers and alliance.

4. Transformation referred to various human resource actions proceeded by human resource transformation role-led changes with new organizational transformation and corporate culture changes when restructuring the organizational 
structure. The practical methods in culture, employee relationship, and organizational teams were covered.

\subsection{Research hypothesis}

Dery and MacCormick (2012) proposed the idea of technical parameters, revealing the applicability of management innovation in the strategy planning process of a business. A business deciding to enter a market with strategies was likely to adopt dominant management innovation, while the followers acquire the business niche with the powerful development capabilities and rapid response capabilities. Hung et al. (2012) indicated that strategic orientation often correlated to management innovation, including educational training, salary and welfare, and employee relationship management set in specific issues. Kappelman et al. (2013) mentioned that many high-performance businesses would apply low-cost, innovative, or differential strategic orientation with Management Innovation, like different salary and welfare; on the contrary, low-performance companies presented weaker salary and Management Innovation. Aiming at the research on management practice and organizational performance in Taiwan, McLaren et al. (2011) indicated that an organization would apply different strategies with human resource management practice. From above discussions, organizational Management Innovation correlates to organizational strategies, and management innovation would change with strategic orientation. It is therefore inferred in this study that

H1: Strategic orientation presents positive effects on Management Innovation.

Williamson et al. (2013) mentioned that the major points of strategic human resource management appeared on the fit of human resource systems, policies, and measures with organizational objectives and various functions, which was the key in effective human resource management. From the contingency perspective of human resource management, the role should complement to organizational strategic orientation (Kane and Borgatti 2011). Tallon and Pinsonneault (2011) divided organizational strategic orientation into different types to discuss the human resource management practice. When an organization applied innovative strategic orientation, the human resource management role should emphasize the employee relationship, interaction, and coordination. When high-quality strategic orientation was adopted, the human resource management role should allow the employees highly participating in decision-making in order to present the organizational commitment. From the viewpoint of culture, Weske (2012) explained the link between human resource management role and strategic orientation and indicated that cost- 
led strategic orientation required disciplinary and detailed culture, while differential strategic orientation required encouraging, innovative, and risky culture. Strategic orientation could establish and maintain proper organizational culture and further affect human resource management role. It is therefore inferred in this study that

$\mathrm{H} 2$ : Strategic orientation reveals positive effects on human resource management role.

Aiming at research on human resource roles, Black (2011) indicated that $41.2 \%$ human resource management roles presented on management innovation. In face of innovative environments with inconsistent, innovative, and turbulent situations, human resource managers have to cultivate more innovation to cope with potential demands. In this case, human resource management role would be more multiple and complicated under external environmental pressure and innovative demands. Kane and Borgatti (2011) mentioned that departments stressing on management innovation would present distinct human resource management roles from general practice, especially emphasize the management innovation of human resource development, provide double-track career development, create high-efficiency teams, and revise reward systems (Chung 2012). Wang and Cheng (2012) explained that management innovation presented a different possibility of innovation with new forms or new specific actions; but it was actually the change of human resource roles. In the innovation process with different dimensions, organizational systems also evolve distinctly. From the viewpoint of management innovation, human resource management roles are also changing. The mutual effects therefore exist in the two dimensions. It is further inferred that

H3: Management innovation shows positive effects on human resource management role.

\section{RESEARCH METHODOLOGY DESIGN}

\subsection{Operational definition and measurement of variable}

\subsubsection{Strategic orientation}

Strategic orientation is divided into three dimensions of cost orientation, quality orientation, and innovation orientation. The scale is revised from the scale proposed by Tallon and Pinsonneault (2011). The overall reliability coefficient appear cost orientation 0.83 , quality orientation 0.82 , and innovation orientation 0.85 . 


\subsubsection{Management innovation}

Management innovation is divided into structural innovation and process innovation. The scale is revised from the scale proposed by Williamson et al. (2013). The overall reliability coefficient shows structural innovation 0.87 and process innovation 0.80 .

\subsubsection{Human resource management role}

Human resource management role contained four dimensions of transaction, translation, transition, and transformation. The scale is revised from the scale proposed by Kane and Borgatti (2011). The overall reliability coefficient presents transaction 0.89 , translation 0.82 , transition 0.82 , and transformation 0.82 .

\subsection{Research subject}

Top ten businesses in Fujian Province, including State Grid Electric Power Co., Ltd., Top Victory Electronics Co., Ltd., Dell (Xiamen) Co., Ltd., Dell (China) Co., Ltd., Fujian Refining and Petrochemical Co., Ltd., Sanming Steel (Group) Co., Ltd. Fujian, Sianglu Petrochemicals, Au Optronics Corp., Longyan Tobacco Industrial Co., Ltd., and HuaYang Electric, are selected as the research subjects. Total 500 copies are distributed and 376 valid copies are retrieved, with the retrieval rate $75 \%$.

\subsection{Verification of reliability and validity analysis}

The reliability of the research dimensions achieves above 0.7 , revealing the high reliability. The construct validity of the scales is analyzed with Confirmatory Factor Analysis. From Table 1, the scales present favorable convergent validity and construct validity.

Table 1. Confirmatory factors

\begin{tabular}{l|l|l}
\hline Dimension & Overall fit & Analysis result \\
\hline Strategic orientation & $\begin{array}{l}\mathrm{X} 2=0(\mathrm{P}<0.001) ; \mathrm{DF}=0 ; \mathrm{GFI}=1.00 ; \\
\mathrm{CFI}=1.00\end{array}$ & Favorable overall model fit \\
\hline Management innovation & $\begin{array}{l}\mathrm{X} 2=0(\mathrm{P}<0.001) ; \mathrm{DF}=0 ; \mathrm{GFI}=1.00 ; \\
\mathrm{CFI}=1.00\end{array}$ & Favorable overall model fit \\
\hline $\begin{array}{l}\text { Human resource } \\
\text { management role }\end{array}$ & $\begin{array}{l}\mathrm{X} 2=0(\mathrm{P}<0.001) ; \mathrm{DF}=0 ; \mathrm{GFI}=1.00 ; \\
\mathrm{CFI}=1.00\end{array}$ & Favorable overall model fit \\
\hline
\end{tabular}




\section{ANALYSIS RESULT}

\subsection{Correlation analysis}

From Table 2, strategic orientation, management innovation, and human resource management role present significant correlations, revealing the multicollinearity among the dimensions. Niehoff and Moorman (1993) suggested solving such a problem with nested model analysis. The remarkable correlation among dimensions also shows the consistency with the research hypotheses.

Table 2. Correlation analysis

\begin{tabular}{l|c|c|c|c}
\hline Dimension & $\alpha$ & $\begin{array}{c}\text { Strategic } \\
\text { orientation }\end{array}$ & $\begin{array}{c}\text { Management } \\
\text { innovation }\end{array}$ & $\begin{array}{c}\text { Human resource } \\
\text { management role }\end{array}$ \\
\hline Strategic orientation & 0.88 & & & \\
\hline Management innovation & 0.82 & $0.28^{* *}$ & & \\
\hline $\begin{array}{l}\text { Human resource } \\
\text { management role }\end{array}$ & 0.83 & $0.22^{* *}$ & $0.36^{* *}$ & \\
\hline
\end{tabular}

Note: $* *$ stands for $\mathrm{p}<0.01$

\subsection{Discussion of theoretical model}

The research results are displayed as the following figure. In this study, the path coefficient achieving the significance is denoted with a solid line, while a dotted line is used for the path coefficient not reaching the significance. Apparently, the path coefficients of all variables achieve the significance, revealing the convergent validity. In other words, they conform to the basic requirement for the analysis model. According to the goodness-of-fit indices GFI $=0.977$, AGFI $=$ 0.926 , $\mathrm{RMSEA}=0.03$, and $\mathrm{CFI}=0.962$, the model fit is verified; in other words, the research model conforms to the theory and presents validity.

\subsection{Discussion of research hypothesis}

Nested model is utilized for the research hypotheses. Chi-square test is used as each nested model appears a degree of freedom difference. For this reason, the path coefficient being set 0 is significant when the difference of chi-square value between the nested model and the theoretical model achieves the significance. The research result shows the model reaching the significance; the nested model analysis is shown in Table 3, and the hypothesis verification is displayed in Table 4. 


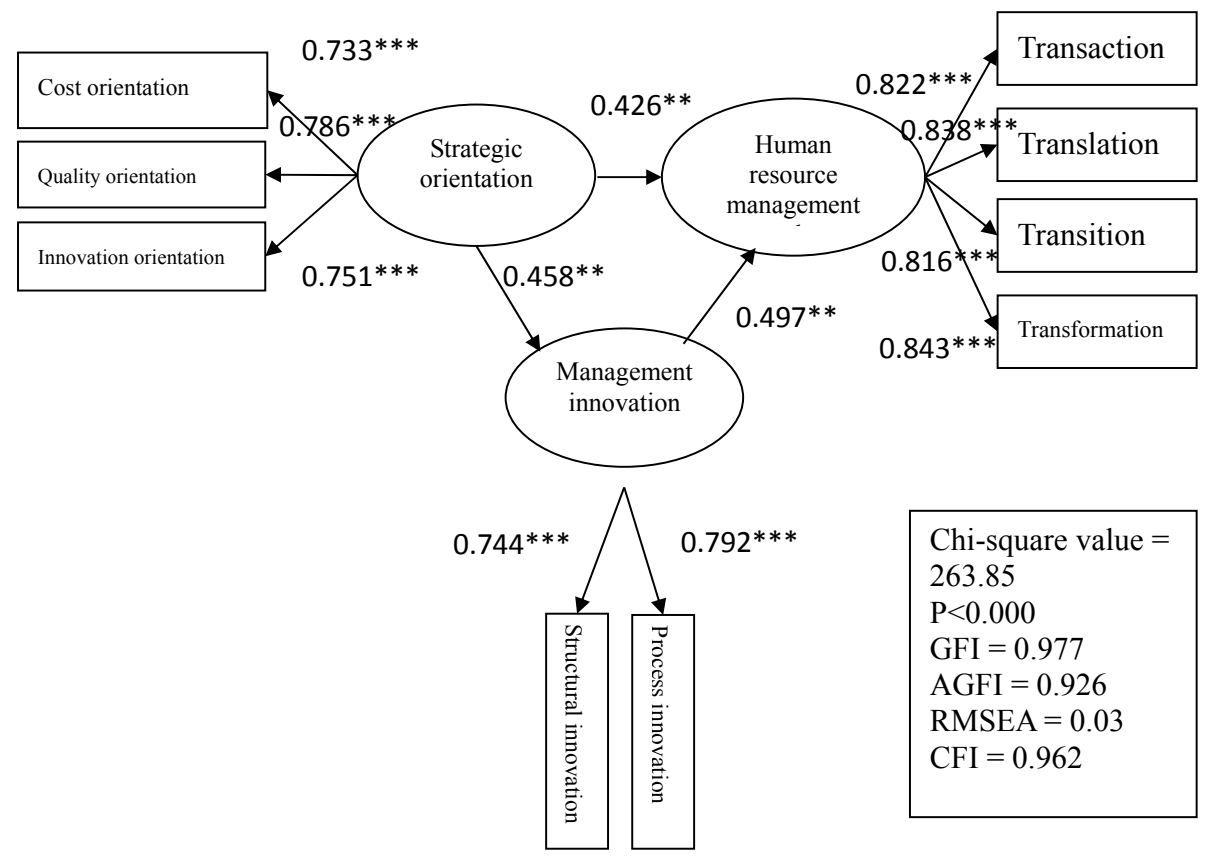

Figure 1. Path diagram

Note: $* *$ stands for $\mathrm{p}<0.01, * * *$ for $\mathrm{p}<0.001$

Table 3. Nested model analysis

\begin{tabular}{l|c|c|c|c|c}
\hline Model & $\chi^{2}$ & $\Delta \chi^{2}$ & GFI & CFI & RMSEA \\
\hline Theoretical model & 263.85 & & 0.977 & 0.962 & 0.03 \\
\hline Model 1: hypothesis verification & 268.18 & $4.33^{*}$ & 0.977 & 0.962 & 0.03 \\
\hline Model 2: hypothesis verification & 273.45 & $5.27 *$ & 0.977 & 0.962 & 0.03 \\
\hline Model 3: hypothesis verification & 279.56 & $6.11^{*}$ & 0.977 & 0.962 & 0.03 \\
\hline
\end{tabular}

Note: * stands for $\mathrm{p}<0.005$

Table 4. Hypothesis verification

\begin{tabular}{l|c|c|c|c}
\hline $\begin{array}{l}\text { Research } \\
\text { hypothesis }\end{array}$ & Correlation & Empirical result & P & Result \\
\hline H 1 & + & 0.458 & 0.00 & supported \\
\hline H 2 & + & 0.426 & 0.00 & supported \\
\hline H 3 & + & 0.497 & 0.00 & supported \\
\hline
\end{tabular}




\section{CONCLUSION}

According to the statistical analysis, the hypothesis of strategic orientation towards management innovation (H1) is supported, proving the remarkably positive effects of strategic orientation on management innovation. The hypothesis of management innovation towards human resource management role (H2) is supported, proving the notable positive effects of management innovation on human resource management role. The hypothesis of strategic orientation towards human resource management role (H3) is supported, proving the significantly positive effects of strategic orientation on human resource management role. It reveals that when an organization promotes different human resource innovation to cope with strategic trend, it has to change the current management dilemma and the appearance of human resource department. Human resources could appear distinct evolution on transaction, translation, transition, and transformation because of different innovative plans. Domestic research on management innovation is little. Especially, the definitions of dimensions might not completely cover the entire meaning of management innovation. This study tends to conclude and explore domestic and international studies to provide a rough primer for management innovation issues. The concept of management innovation presents practical meanings and academic research value. By establishing and developing such a concept, the research on human resources could exceed the past distribution and enter the innovative practice with higher strategic level and become the weapon for business transformation and integration. The relevant research could directly create value for an organization through definite management innovation.

\section{SUGGESTION}

To conclude the results and findings, practical suggestions are proposed as below.

1. Current development of management innovation is still low; however, it could be further studied with organizational performance, innovative performance, or management efficiency. In the beginning of management innovation development, a business could refer to the advantages of different industries, such as the training, development, and innovation in finance industry and performance management and salary \& welfare innovation in high-tech industry. In regard to the selection of management innovation, a business needs to consider the focus of organizational strategic orientation on the internal or the external and the sufficient social capital accumulation for practical processes. Besides, the number of organizational personnel and the amount of capital should also be taken into account. 
2. There are various plans which could be enhanced the function or improved for Management Innovation, aiming at different problems in the management system. Nonetheless, a business cannot accept everything with the benchmark or imitate temporarily popular practice. Business strategic orientation should pay attention to not pursuing modern approaches but stress on understanding the theory and practice of such approaches for the proper use in practice.

3. In practice, the research dimensions are transformed to different practice and approach processes. For this reason, it is proposed in this study that any practical functions should match the organizational strategies and consider various conditions as well as relative plans in an organization. Promoting management innovation in a business should be practiced in such a way.

\section{REFERENCES}

Avci, U., Madanoglu, M. and Okumus, F. (2011). Strategic orientation and performance of tourism firms: Evidence from a developing country. Tourism Management, 32(1), 147-157.

Black, K. (2011). Business statistics: For contemporary decision making. (7th ed.). United States of America: John Wiley \& Sons.

Chen, Y., Wang, Y., Nevo, S., Jin, J., Wang, L. and Chow, W.S. (2013). IT capability and organizational performance: the roles of business process agility and environmental factors. European Journal of Information Systems, 1-17.

Chung, H.F. (2011). Market orientation, guanxi, and business performance. Industrial Marketing Management, 40(4), 522-533.

Chung, H.F. (2012). Export market orientation, managerial ties, and performance. International Marketing Review, 29(4), 403-423.

Dery, K. and MacCormick, J. (2012). Managing mobile technology: the shift from mobility to connectivity. MIS Quarterly Executive, 11(4), 159-173.

Deshpande, R., Grinstein, A., Kim, S.-H. and Ofek, E. (2013). Achievement motivation, strategic orientations and business performance in entrepreneurial firms: How different are Japanese and American founders? International Marketing Review, 30(3), 231-252.

Engeström, Y. and Glăveanu, V. (2012). On third generation activity theory: Interview with Yrjö Engeström. Europe's Journal of Psychology, 8(4), 515-518.

Fenton, C. and Langley, A. (2011). Strategy as practice and the narrative turn. Organization Studies, 32(9), 1171-1196.

Hung, W.H., McQueen, R.J., Ku, C.Y. and Chang, L.M. (2012). Aligning website with enterprise success: An evaluative approach. Journal of Computer Information Systems, 52(4), 49-58.

Hwang, W.J. and Tsai, C.H. (2011). Examining the effect of alignment between information system strategy and environmental uncertainty on SCM performance. The 2011 International Conference on Business and Information, Taiwan.

Ismail, K.M., Ford, Jr. D.L., Wu, Q. and Peng, M.W. (2013). Managerial ties, strategic initiatives, and firm performance in Central Asia and the Caucasus. Asia Pacific Journal of Management, $30(2), 433-446$.

Kane, G.C. and Borgatti, S.P. (2011). Centrality-IS proficiency alignment and workgroup performance. MIS Quarterly, 35(4), 1063-1078. 
Kappelman, L., McLean, E., Luftman, J. and Johnson, V. (2013). Key Issues of IT organizations and their leadership: The 2013 SIM IT trends study. MIS Quarterly Executive, 12(4), 227-240.

Komninos, A., Plessas, A., Stefanis, V. and Garofalakis, J.D. (2011). Context dimensionality reduction for mobile personal information access. In KDIR, 493-498.

Luftman, J. and Derksen, B. (2012). Key issues for IT executives 2012: Doing more with less. MIS Quarterly Executive, 11(4), 207-218.

Marti, I., Courpasson, D. and Barbosa, S.D. (2013). Living in the fishbowl: Generating an entrepreneurial culture in a local community in Argentina. Journal of Business Venturing, 28(1), $10-29$.

McLaren, T.S., Head, M.M., Yuan, Y. and Chan, Y.E. (2011). A multilevel model for measuring fit between a firm's competitive strategies and information systems capabilities. MIS Quarterly, 35(4), 909-929.

Niehoff, B.P. and Moorman, R.H. (1993). Justice as a mediator of the relationship between methods of monitoring and organizational citizenship behavior. Academy of Management Journal, 36(3), 527-556.

Sheng, S., Zhou, K.Z. and Li, J.J. (2011). The effects of business and political ties on firm performance: Evidence from China. Journal of Marketing, 75(January), 1-15.

Tallon, P.P. and Pinsonneault, A. (2011). Competing perspectives on the link between strategic information technology alignment and organizational agility: Insights from a mediation model. MIS Quarterly, 35(2), 463-484.

Wang, Y.S. and Cheng, T. (2012). Saturated Model in Dynamic Theory on Chain Channel of Taiwan 3C Electric Appliances: Perspective of Dynamic Competition.

Weske, M. (2012). Business Process Management: Concepts, Languages, Architectures. Springer.

Williamson, D., Cooke, P., Jenkins, W. and Moreton, K.M. (2013). Strategic Management and Business Analysis. Routledge. 